University of Nebraska - Lincoln

DigitalCommons@University of Nebraska - Lincoln

Faculty Publications from the Harold W. Manter Laboratory of Parasitology

$2-2007$

\title{
Two New Species of Rhabdias (Nematoda: Rhabdiasidae) from the Marine Toad, Bufo marinus (L.) (Lissamphibia: Anura: Bufonidae), in Central America
}

Yuriy Kuzmin Institute of Zoology (Kyiv, Ukraine)

Vasyl V. Tkach

University of North Dakota

Daniel R. Brooks

University of Toronto, dnlbrooks@gmail.com

Follow this and additional works at: https://digitalcommons.unl.edu/parasitologyfacpubs

Part of the Parasitology Commons

Kuzmin, Yuriy; Tkach, Vasyl V.; and Brooks, Daniel R., "Two New Species of Rhabdias (Nematoda: Rhabdiasidae) from the Marine Toad, Bufo marinus (L.) (Lissamphibia: Anura: Bufonidae), in Central America" (2007). Faculty Publications from the Harold W. Manter Laboratory of Parasitology. 270. https://digitalcommons.unl.edu/parasitologyfacpubs/270

This Article is brought to you for free and open access by the Parasitology, Harold W. Manter Laboratory of at DigitalCommons@University of Nebraska - Lincoln. It has been accepted for inclusion in Faculty Publications from the Harold W. Manter Laboratory of Parasitology by an authorized administrator of DigitalCommons@University of Nebraska - Lincoln. 


\title{
TWO NEW SPECIES OF RHABDIAS (NEMATODA: RHABDIASIDAE) FROM THE MARINE TOAD, BUFO MARINUS (L.) (LISSAMPHIBIA: ANURA: BUFONIDAE), IN CENTRAL AMERICA
}

\author{
Yuriy Kuzmin, Vasyl V. Tkach ${ }^{\star} †$, and Daniel R. Brooksł \\ Department of Parasitology, Institute of Zoology, 15 Bogdan Khmelnytskyi Street, Kyiv, 01601 Ukraine. e-mail: vasyl.tkach@und.nodak.edu
}

\begin{abstract}
Two new Rhabdias species are described from the lungs of the cane toad Bufo marinus (L.) from Costa Rica and Nicaragua. Rhabdias alabialis n. sp. differs from other known species of the genus by the remarkable morphology of its head end, i.e., the absence of lips or pseudolabia, the slitlike oral opening, and the triangular shape of the buccal capsule in apical view. Rhabdias pseudosphaerocephala $\mathrm{n}$. sp. is identified as a form previously known in Central and South America as Rhabdias sphaerocephala Goodey, 1924, a species initially described from toads in Europe. The new species is differentiated from $R$. sphaerocephala based on head-end morphology and sequences of nuclear rDNA.
\end{abstract}

Species of Rhabdias Stiles et Hassall, 1905, are a globally distributed group of nematodes parasitic in lungs of amphibians and reptiles and include more than 40 nominal species. Fifteen species have been reported from members of the Bufonidae; 11 of them seem to be specific to this host family. In Central and South America, 5 Rhabdias species have been reported from Bufo spp. Two of these, Rhabdias sphaerocephala Goodey, 1924 and Rhabdias fulleborni Travassos, 1926, are known as parasites of Bufo marinus (L.) (Kloss, 1971, 1974).

Beginning in 1996, the Area de Conservacion Guanacaste (ACG) (http://www.acguanacaste.ac.cr) in northwestern Costa Rica has supported an effort to perform an inventory of the eukaryotic parasites of all 940 species of vertebrates living within the ACG (http://www.parasitesrus.com). As part of that project, we collected parasites inhabiting specimens of Bufo marinus. Additionally, Rhabdias spp. have been collected from B. marinus from several localities in western Nicaragua. Examination of that material revealed the presence of 2 distinct Rhabdias species. One of these was identical to nematodes previously reported in Central and South America as $R$. sphaerocephala (Bravo-Hollis and Caballero, 1940; Brenes and BravoHollis, 1959; Kloss, 1971, 1974). Morphological comparison of the worms studied with the original description of $R$. sphaerocephala Goodey, 1924 from Bufo bufo from Great Britain and the material from the same host species from Ukraine, as well as analysis of the DNA sequences, demonstrated substantial differences between South and Central American forms and European forms. The second new species possesses morphological features that readily differentiate it from all known species of the genus. Two new species of Rhabdias are, therefore, described herein.

\section{MATERIALS AND METHODS}

All nematodes were taken from freshly killed hosts. Some of them were fixed in glacial acetic acid and stored in $70 \%$ ethanol, while others were heat-killed in saline and stored in $70 \%$ ethanol. Specimens for molecular analysis were placed directly into $95 \%$ ethanol. Museum

Received 6 February 2006; revised 19 August 2006; accepted 22 August 2006.

* To whom correspondence should be addressed. Department of Biology, University of North Dakota, 1 Campus Drive and Cornell Street, Grand Forks, North Dakota 58202.

$\dagger$ Institute of Parasitology, Polish Academy of Sciences, 51/55 Twarda Street, 00-818 Warsaw, Poland.

$\ddagger$ Department of Zoology, University of Toronto, Toronto, Ontario M5S 3G5, Canada. specimens of $R$. fulleborni were examined. Those included permanent total mounts of neotypes on slides (Museu de Zoologia da Universidade de São Paulo, no. 1650), and material from B. marinus from Bermudas (U.S. National Parasite Collection, nos. 83196 and 87195), stored in alcohol. Specimens of $R$. sphaerocephala for morphological and molecular study were collected from Bufo bufo near Kyiv, Ukraine.

For light microscopy, specimens were cleared in glycerol by gradual evaporation from a 5\% solution of glycerol in $70 \%$ ethanol, or in glycerol-phenol (3:1) solution. Measurements are in micrometers unless otherwise noted. Drawings were made with the aid of a drawing tube.

Nematodes used for SEM were initially fixed in ethanol, then dehydrated in a graded series of ethanol and acetone and dried using hexamethyldisilazane (HMDS) (Ted Pella, Inc., Redding, California) as transition fluid. Dry specimens were mounted on stubs, coated with goldpalladium, and examined using a Hitachi 4700 scanning electron microscope (Hitachi USA, Mountain View, California) at an accelerating voltage of $10-15 \mathrm{kV}$.

For molecular analysis, live worms recovered from the host were rinsed thoroughly in saline and fixed in 95\% ethanol. Genomic DNA was extracted from single specimens of worms according to Tkach and Pawlowski (1999). DNA fragments spanning the $3^{\prime}$ end of 18 S nuclear rDNA gene, ITS region (ITS1 $+5.8 \mathrm{~S}+$ ITS2), and $5^{\prime}$ end of the $28 \mathrm{~S}$ (including variable domains D1-D3) were amplified by PCR on an Eppendorf Master Gradient thermal cycler using forward primer ITS5 (5'-GGAAGTAAAAGTCGTAACAAGG-3') and reverse primer 1500R (5'-GCTATCCTGAGGGAAACTTCG-3').

PCR reactions were performed in a total volume of $51 \mu$ l containing $42 \mu \mathrm{l} \mathrm{H}_{2} \mathrm{O}, 5 \mu \mathrm{T} \mathrm{Taq}$ buffer, $1 \mu \mathrm{l}$ dNTP at a concentration of 10 $\mathrm{pM} / \mu \mathrm{l}, 1 \mu \mathrm{l}$ of each primer at a concentration of $10 \mathrm{pM} / \mu 1,0.25 \mu \mathrm{l}$ of Eppendorf Taq polymerase at a concentration of 5 units/ $\mu 1$, and $1-1.5$ $\mu \mathrm{l}$ of template gDNA extract. The thermocycling profile was as follows: $2 \mathrm{~min}$ denaturation at $94 \mathrm{C}$; then 40 cycles of $30 \mathrm{sec}$ at $94 \mathrm{C}, 30 \mathrm{sec}$ at 52-56 C, $2 \mathrm{~min}$ at $72 \mathrm{C}$; and a final 7-min extension at $72 \mathrm{C}$.

PCR products were purified using Qiagen Qiaquick (Valencia, California) columns and sequenced directly on an ABI Prism 3100 (iil automated capillary sequencer using ABI BigDye ${ }^{\text {(ix }}$ chemistry (Foster City, California) according to manufacturer's protocols. DNA products were sequenced in both directions using the 2 PCR primers and, additionally, internal primers ITS4 $\left(5^{\prime}\right.$-TCCTCCGCTTATTGATATGC- $\left.3^{\prime}\right)$ 300R (5'-CAACTTTCCCTCACGGTACTTG-3'), 300F (5'-CAAGTA CCGTGAGGGAAAGTTG-3'), and ECD2 (5'-CTTGGTCCGTGTTT CAAGACGGG-3'). Contiguous sequences were assembled and edited using Sequencher version 4.1.1 (GeneCodes Corp., Ann Arbor, Michigan) and submitted to GenBank under accession numbers DQ845734DQ845738 (R. pseudosphaerocephala) and DQ845739-DQ845741 ( $R$. sphaerocephala) Sequences were manually aligned and compared using the BioEdit program, version 7.0.1 (Hall, 1999).

\section{DESCRIPTIONS \\ Rhabdias alabialis n. sp. \\ (Figs. 1, 3A)}

General (Based on 50 specimens; measurements are for holotype, followed by limits for 25 paratypes in parentheses. Measurements are presented in micrometers unless otherwise stated. Calculations for the 

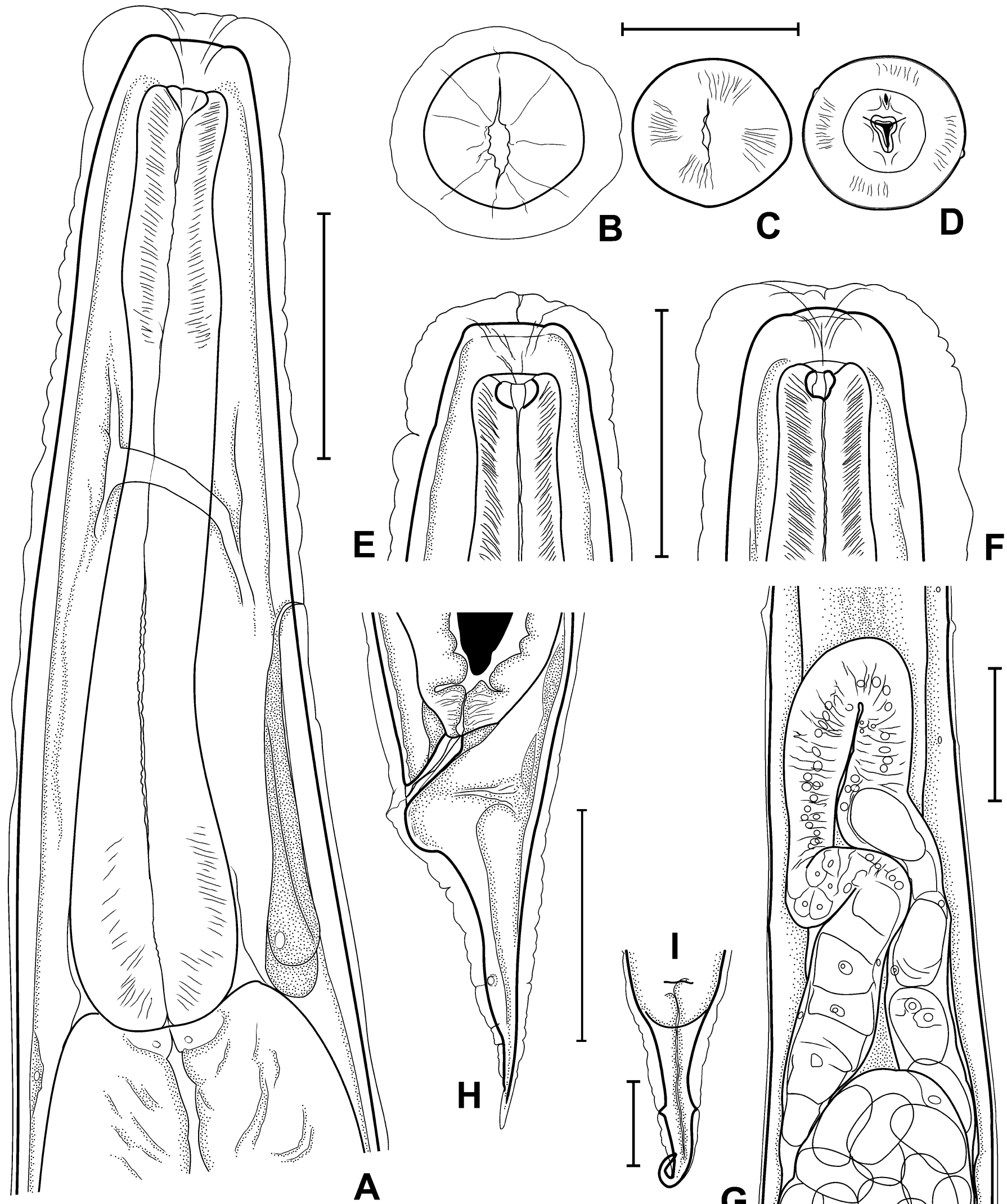
TABLE I. Metric characters of Rhabdias alabialis (type series, $\mathrm{n}=26$ ). Measurements are in micrometers unless otherwise noted. SD, standard deviation; CV, coefficient of variation.

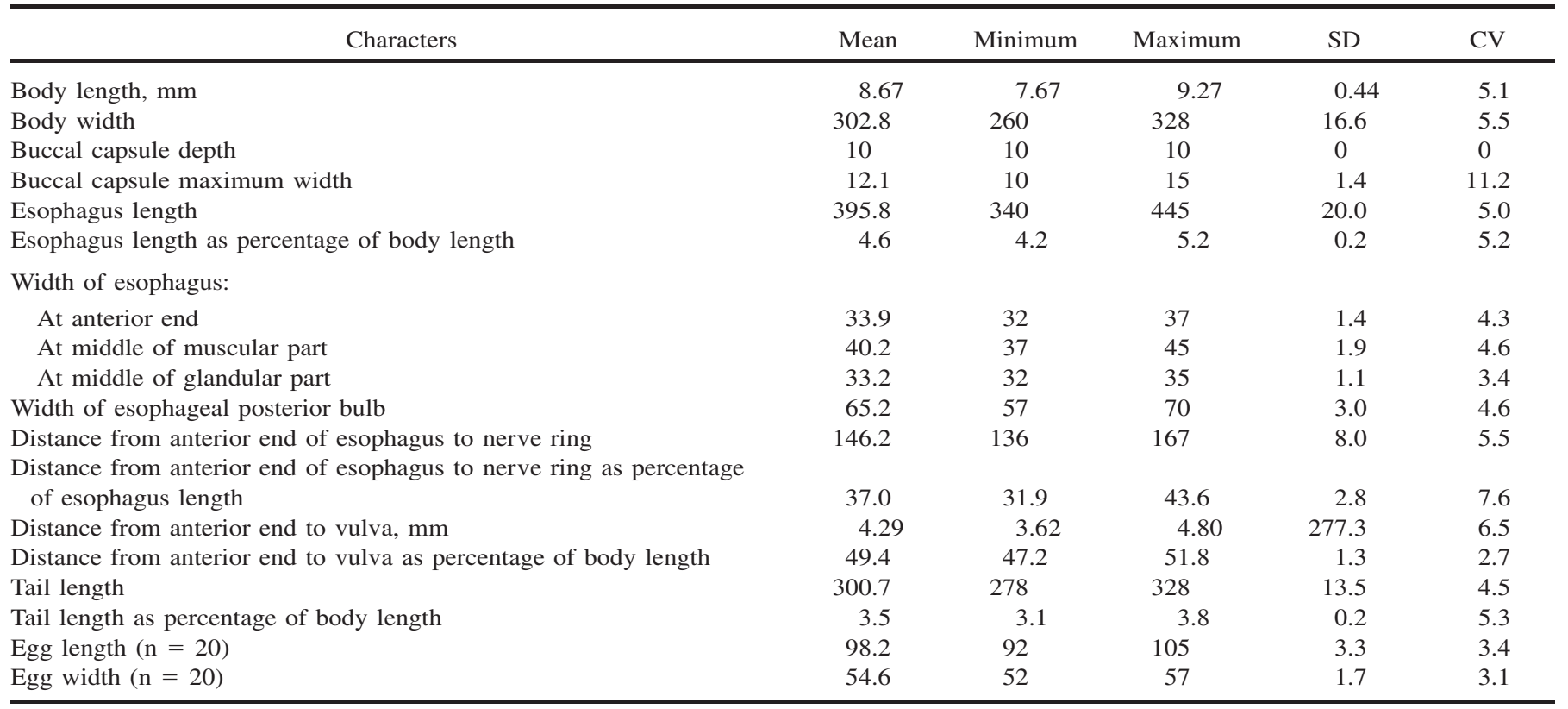

whole sample are given in Table I): Body 7.97 (7.67-9.27) $\mathrm{mm}$ long, 315 (260-328) wide at midbody. Anterior end rounded, posterior end tapering. Outer layers of body cuticle prominently swollen, especially at anterior end, with irregular transverse folds. Oral opening slitlike, orientated dorsoventrally. Eight radial folds of epicuticle surrounding oral opening. Vestibulum 20 (15-25) deep, slitlike in apical view, funnel-shaped in lateral view, lined with folded cuticle. Lips or pseudolabia absent. Buccal capsule (esophastome) triangular in apical view, infundibuliform in lateral view, 10 (10-10) deep, 12 (10-15) wide. Buccal capsule walls (esophorhabdion) dense and thick. Esophagus typical for species of the genus, club-shaped, 389 (340-445) long, with prominent dilation at midlength of anterior muscular part and egg-shaped posterior bulb. Anterior end of esophagus 35 (32-37) wide; maximum width of muscular dilation 37 (37-45); minimum width of glandular part 32 (32$35)$; posterior bulb 65 (57-70) wide. Nerve ring encircling esophagus posterior to its muscular swelling, 148 (136-167) from anterior end of esophagus. Excretory pore posterior to nerve ring. Excretory glands relatively short, approximately half as long as esophagus. Anterior part of intestine wide, thick-walled, with narrow lumen. Intestinal lumen behind posterior limb of genital system wide, filled with black contents. Muscular prerectal sphincter of intestine obvious. Rectum short, straight, lined with thick cuticle. Genital system amphidelphic. Vulva transverse, near midbody, $3.95(3.62-4.80) \mathrm{mm}$ from anterior end. Vagina reduced. Uteri long, straight, thin-walled, filled with numerous eggs; most eggs containing larvae. Both limbs of genital system bending at region of seminal receptacles. Ovaries (syngonia) situated beside intestine; each ovary far overlapping level of vulva. Tail conical, 303 (278-328) long, with prominent ventral postanal inflation of body wall. Phasmids comparatively large, conical, situated at middle of tail length. Tail tip lacking cuticular swelling.

\section{Taxonomic summary}

Type host: marine toad or cane toad Bufo marinus (L.) (Anura: Bufonidae).

Site of infection: Lungs.

Type locality: Puesto Rio Murcielago, Sector Murcielago, Area de Conservacion Guanacaste, Guanacaste Province, Costa Rica.

Other localities: Sector Santa Rosa: Rio Cuajiniquil, at crossing of Cafetal Road $\left(10^{\circ} 52.51^{\prime} \mathrm{N}, 85^{\circ} 36.42^{\prime} \mathrm{W}\right.$, elevation $\left.281 \mathrm{~m}\right)$; Quebrada Costa Rica, Camino Playa Naranjo ( $10^{\circ} 50.04^{\prime} \mathrm{N}, 85^{\circ} 37.29^{\prime} \mathrm{W}$, elevation 287 m); Area Administrativa, Estacion Santa Rosa, Quebrada Guapote, Camino Rosa Maria $\left(10^{\circ} 49.22^{\prime} \mathrm{N}, 85^{\circ} 36.51^{\prime} \mathrm{W}\right.$, elevation $\left.275 \mathrm{~m}\right)$; Sector
San Gerardo: Estacion San Gerardo $\left(10^{\circ} 52.50^{\prime} \mathrm{N}, 85^{\circ} 23.21^{\prime} \mathrm{W}\right.$, elevation $605 \mathrm{~m}$ ); Rio Pizote between Brasilia and Dos Rios $\left(10^{\circ} 56.02^{\prime} \mathrm{N}\right.$, $85^{\circ} 24.05^{\prime} \mathrm{W}$ ), Area de Conservacion Guanacaste, Guanacaste Province, Costa Rica.

Type specimens deposited: Holotype: USNPC 98143; paratypes: USNPC 98144.

Etymology: The species name is given in reference to the absence of lips characteristic of this species.

\section{Remarks}

Rhabdias alabialis is readily distinguishable from all other species of the genus by its unique head-end morphology, i.e., its buccal capsule shape (triangular in apical view), absence of lips, and slitlike oral opening. With regard to the latter character, $R$. alabialis is similar to Rhabdias bicornis Lu, 1934, described from Bufo spp. in China. Rhabdias bicornis, however, possesses 2 prominent lateral pseudolabia (Lu, 1934; Kung and $\mathrm{Wu}, 1945$; Hsu, 1960), which are absent in $R$. alabialis. Rhabdias bicornis also lacks the dilation of the esophagus in the midregion of its muscular part, which is present in $R$. alabialis.

\section{Rhabdias pseudosphaerocephala n. sp.}

$$
\text { (Figs. 2, 3B) }
$$

General (Based on 26 specimens; measurements are for holotype, followed by limits for 25 paratypes in parentheses. Measurements are presented in micrometers unless otherwise stated. Calculations for the whole sample are given in Table II): Body 7.90 (6.17-9.60) $\mathrm{mm}$ long and 330 (290-380) wide at midlength. Anterior end rounded, posterior end tapered. Body cuticle swollen, especially on head end, and covered with irregular transverse folds. Oral opening round, surrounded with 4 submedian lips overhanging edge of oral opening. Two lateral pseudolabia rounded, comparatively small. Each submedian lip and pseudolabium bearing small papilla on the top. Amphids porelike, situated on pseudolabia. Buccal capsule funnel-shaped, thick-walled, 10 (7-12) deep and 17 (15-17) wide. Esophagus club-shaped, dilation of anterior muscular part present. Esophagus length 410 (400-460) or 5.2\% (4.4$6.5 \%$ ) of body length. Anterior end of esophagus 37 (35-40) wide; maximum width of muscular dilation 42 (40-50) wide; minimum width of glandular part 37 (35-42); posterior bulb 72 (67-85) wide. Nerve ring encircling esophagus posterior to its muscular swelling, 160 (140190) from anterior end of esophagus (39.0\% [33.3-43.2\%] of esophagus length). Excretory pore posterior to nerve ring. Shape of intestine and 

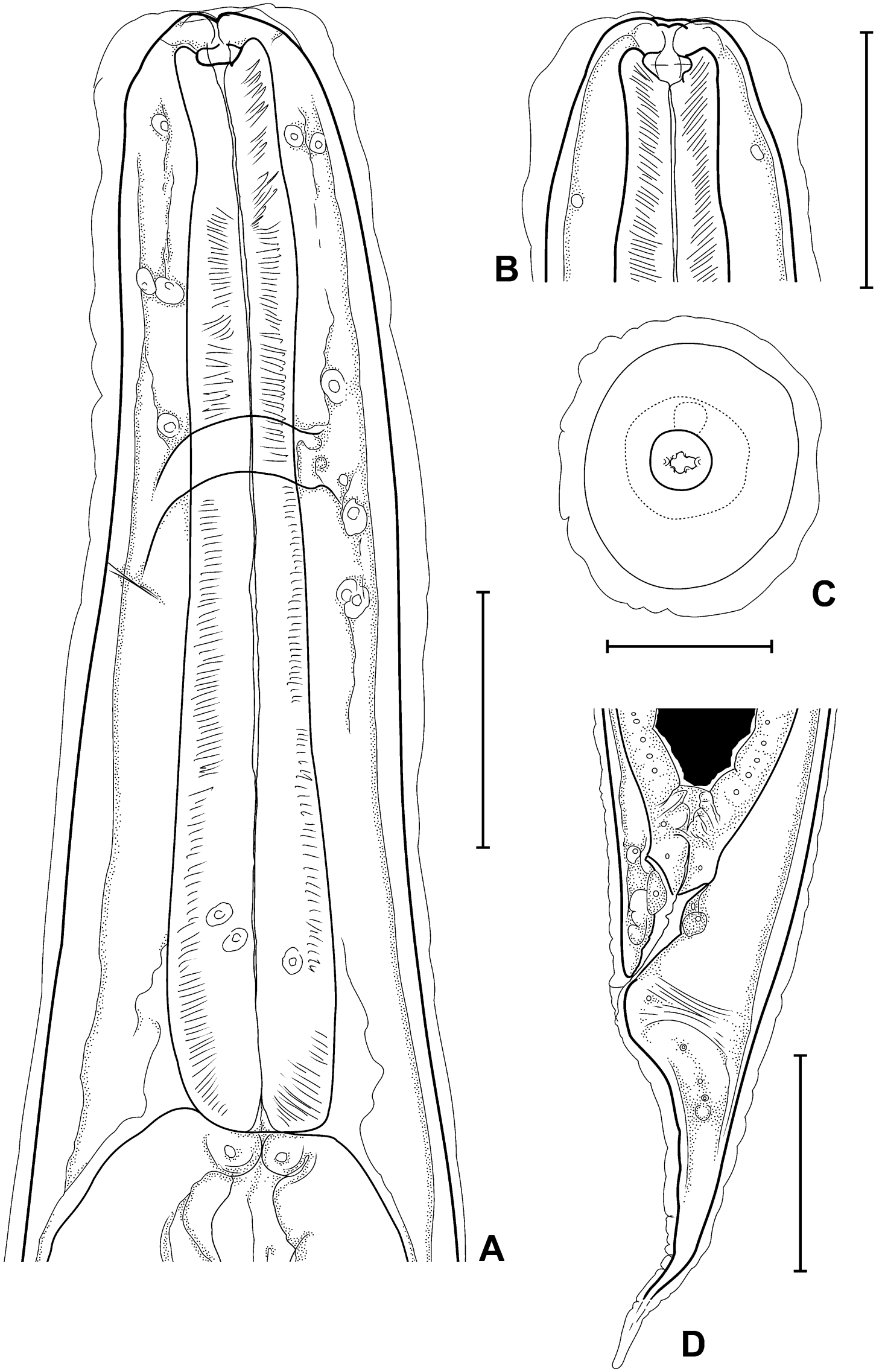

Figure 2. Rhabdias pseudosphaerocephala n. sp. (A) Anterior part of the body, lateral view. (B) Head end, dorsoventral view; (C) head end, apical view; (D) tail end, lateral view. Scale bars: A, B $=0.1 \mathrm{~mm} ; \mathrm{C}=0.05 \mathrm{~mm} ; \mathrm{D}=0.2 \mathrm{~mm}$. 

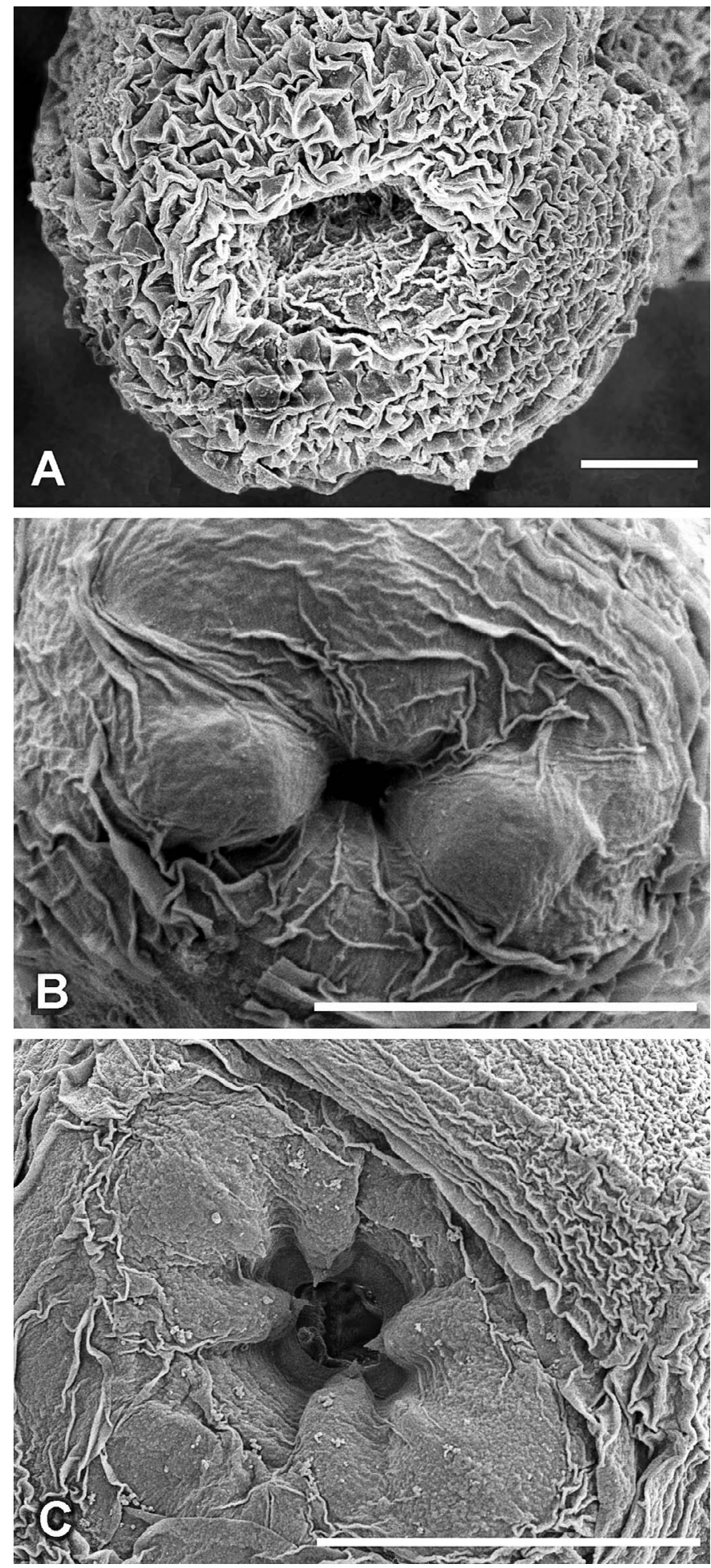

FiguRE 3. (A) Rhabdias alabialis n. sp. (B) Rhabdias pseudosphaerocephala $\mathrm{n}$. $\mathrm{sp}$. (C) Rhabdias sphaerocephala. Scale bars: $\mathrm{A}=$ $10 \mu \mathrm{m}, \mathrm{B}=30 \mu \mathrm{m}, \mathrm{C}=30 \mu \mathrm{m}$

rectum same as in previous species, as well as genital system structure. Vulva almost equatorial, distance from anterior end to vulva 3.92 (3.30$4.95) \mathrm{mm}$, or $49.7 \%(47.5-53.4 \%)$ of body length. Tail comparatively short, conical. Tail length 350 (310-410), or $4.4 \%(3.7-5.0 \%)$ of body length.

\section{Taxonomic summary}

Type host: Bufo marinus (L.) (Anura: Bufonidae), marine toad or cane toad.

Site of infection: Lungs.

Type locality: City of Leon, Leon Province, Nicaragua $\left(12^{\circ} 25.57^{\prime} \mathrm{N}\right.$, $86^{\circ} 52.53^{\prime} \mathrm{W}$.

Other localities: City of Chinandega, Chinandega Province, Nicaragua; Sector Santa Rosa: Quebrada Costa Rica, Camino Playa Naranjo $\left(10^{\circ} 50.04^{\prime} \mathrm{N}, 85^{\circ} 37.29^{\prime} \mathrm{W}\right)$; Area Administrativa, Estacion Santa Rosa; Rio Cuajiniquil, at crossing of Cafetal Road $\left(10^{\circ} 52.51^{\prime} \mathrm{N}, 85^{\circ} 36.42^{\prime} \mathrm{W}\right)$ Sector San Gerardo: Estacion San Gerardo $\left(10^{\circ} 52.50^{\prime} \mathrm{N}, 85^{\circ} 23.21^{\prime} \mathrm{W}\right)$ Sector Santa Elena: Santa Elena, Laguna los Jicaros; Sector Maritza: Maritza station $\left(10^{\circ} 57.40^{\prime} \mathrm{N}, 85^{\circ} 29.30^{\prime} \mathrm{W}\right)$, Area de Conservacion Guanacaste, Guanacaste Province, Costa Rica.

Type specimens deposited: Holotype: USNPC 98145; paratypes: USNPC 98146.

\section{Remarks}

Rhabdias pseudosphaerocephala $\mathrm{n}$. $\mathrm{sp}$. is most similar to $R$. fulleborni Travassos, 1926 by general morphology, host specificity, and geographic distribution. Detailed differentiation between the 2 species was provided by Kloss $(1971,1974)$ who identified $R$. pseudosphaerocephala $\mathrm{n}$. sp. as $R$. sphaerocephala Goodey, 1924. Examination of type material of $R$. fulleborni and material from the USNP confirmed that the species differs from $R$. pseudosphaerocephala by a more slender body, especially at the anterior end, and a narrower anterior-most part of the esophagus. In addition, $R$. pseudosphaerocephala $\mathrm{n}$. sp. differs from $R$. fulleborni by having a relatively shorter esophagus; Figure 4 depicts the results of comparing the relative length of the esophagus in $R$. fulleborni and $R$. pseudosphaerocephala based on measurements published by Kloss (1971) and our data. Both samples of $R$. pseudosphaerocephala measured in present study appeared to be almost identical to " $R$. sphaerocephala" studied by Kloss (1971); all 3 samples were clearly different from $R$. fulleborni.

The specimens described here as $R$. pseudosphaerocephala $\mathrm{n}$. $\mathrm{sp}$. were first identified in Central and South America (Bravo-Hollis and Caballero, 1940; Brenes and Bravo-Hollis, 1959; Kloss, 1971, 1974) as R. sphaerocephala Goodey, 1924, originally described from the European common toad (B. bufo) (Goodey, 1924). The 2 species resemble each other by the presence of cuticular swelling at the head end. In $R$. sphaerocephala, however, the cuticular swelling on the head end is distinctly separated from cuticle covering the rest of the body (Goddey, 1924; Kuzmin, 1997). The 2 species also substantially differ by the head-end morphology. Rhabdias sphaerocephala possesses 6 lips surrounding an oral opening at some distance from its edge (Fig. 3C), whereas in $R$. pseudosphaerocephala, the oral opening is surrounded by 4 submedian lips overhanging the edge of oral opening and 2 lateral pseudolabia (Fig. 3B). In R. sphaerocephala, the buccal capsule is not surrounded by esophageal tissue (Kuzmin, 1997), whereas in R. pseudosphaerocephala, the buccal capsule walls are completely surrounded by esophageal tissue (Figs. 2A, B). In addition, $R$. sphaerocephala possesses a relatively longer esophagus, as shown in Figure 5.

The amplified and sequenced fragment of nuclear rDNA included the complete ITS region (ITS1, 5.8S, ITS2) and fragment at the $5^{\prime}$ end of the $28 \mathrm{~S}$ gene, including variable domains D1-D3. Alignment require only 2 gaps because the species under investigation were obviously closely related. Alignment of sequenced fragments was 1,607 bases long; sequences of both $R$. pseudosphaerocephala $\mathrm{n}$. sp. and $R$. sphaerocephala were 1,606 bases long. Twenty of 1,607 alignment sites $(1.44 \%)$ were variable. This level of variability appears meaningful considering that sequences obtained from 7 specimens of $R$. pseudosphaerocephala $\mathrm{n}$. sp., collected at different times from 2 different localities in Nicaragua and 3 in Costa Rica, showed no intraspecific variation. Similarly, sequences obtained from 3 specimens of $R$. sphaerocephala from Ukraine were identical. Variable sites were scattered along alignment with the majority in the ITS 1 region. Thus, molecular data strongly support observed morphological differences between $R$. pseudosphaerocephala $\mathrm{n}$. sp. and $R$. sphaerocephala.

\section{DISCUSSION}

Bilateral symmetry of cephalic structures has been reported for several Rhabdias species. Baker (1978) described lateral 
TABLE II. Metric characters of Rhabdias pseudosphaerocephala (type series, $\mathrm{n}=26$ ). Measurements are in micrometers unless otherwise noted. $\mathrm{SD}$, standard deviation; $\mathrm{CV}$, coefficient of variation.

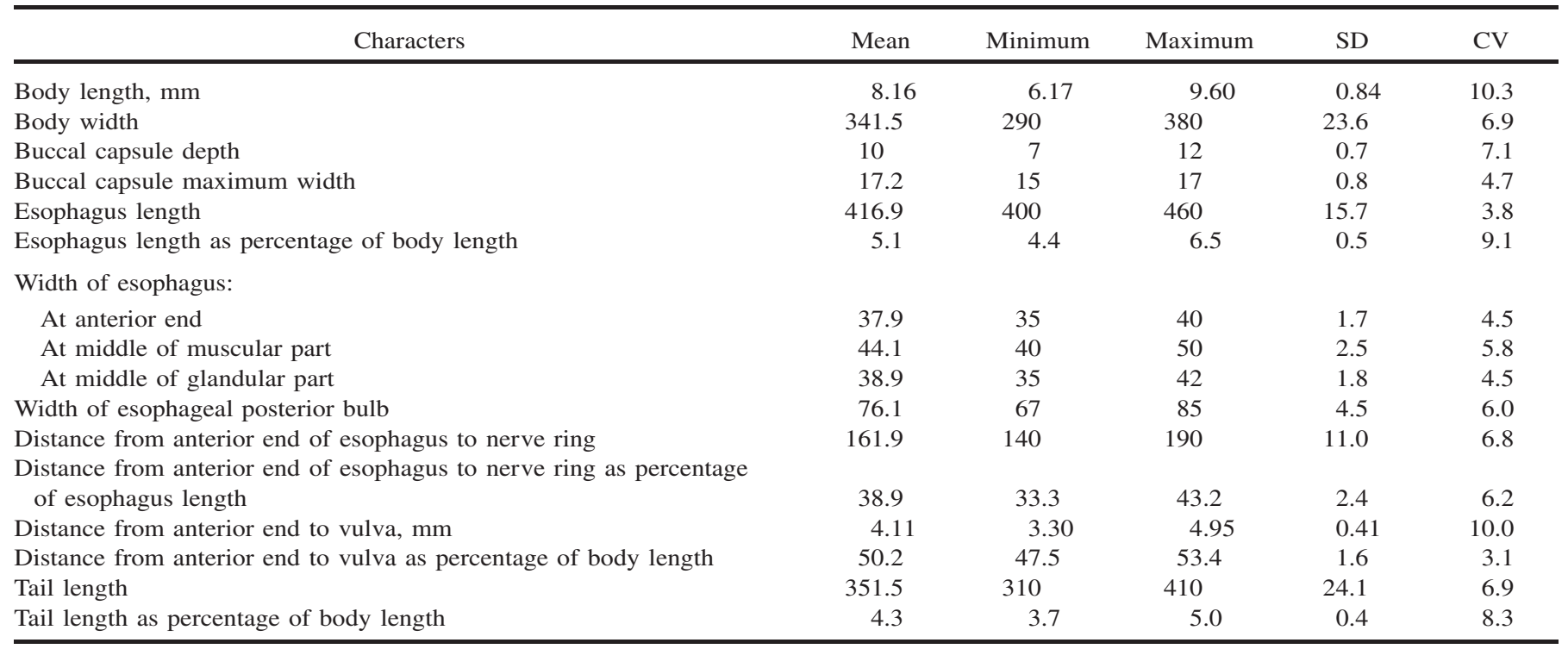

pseudolabia in 2 North American species, i.e., Rhabdias americanus Baker, 1978 and Rhabdias ranae Walton, 1929 (the specimens of $R$. ranae described by Baker, 1978, are considered here as belonging to Rhabdias bakeri nov. sp. [Tkach et al., 2006]). Similar structures were described in Rhabdias africanus Kuzmin, 2001 (Kuzmin, 2001). However, in all these species, the submedian lips are present, at least in the shape of "protuberances" (sensu Baker, 1978). In R. bicornis, lips are completely replaced with lateral pseudolabia extending anteriorly (Lu, 1934). Subadults of $R$. americanus and $R$. ranae lack lateral pseudolabia, and their formation occurs during the maturation of adult stage (Baker, 1979). In the present study, we dealt only with gravid specimens of $R$. alabialis and all of them lacked any sign of lateral pseudolabia.

The identification of some Rhabdias from B. marinus as $R$. sphaerocephala was previously questioned by Chabaud et al. (1961), Hartwich (1975), and Baker (1978). In the present

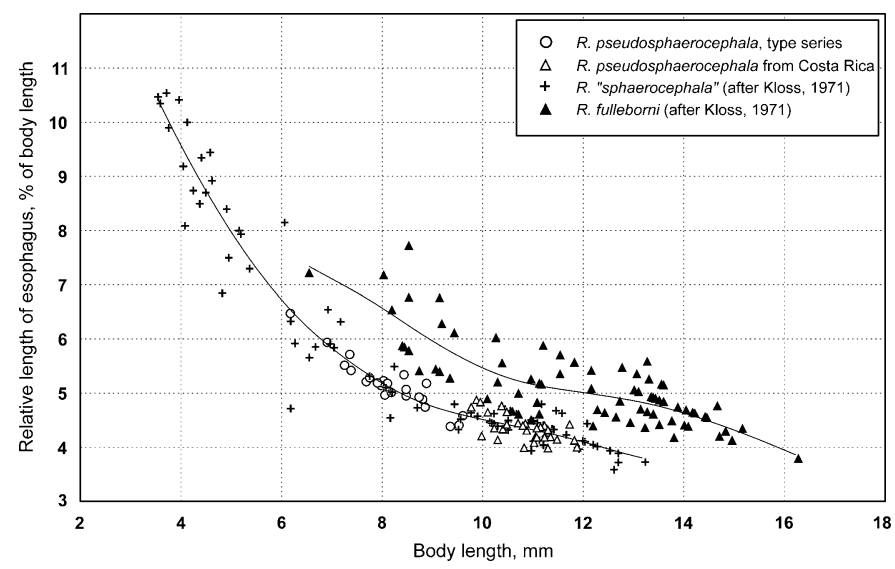

FIGURE 4. Relationship of the relative length of esophagus (percentage of total length) to the total length in $R$. pseudosphaerocephala sp. nov. and $R$. fulleborni. Lines $=$ the least-squares lines. study, we found both morphological and molecular differences among the European $R$. sphaerocephala and the American $R$. pseudosphaerocephala $\mathrm{n}$. sp. This differentiation is in agreement with the fact that almost all known Rhabdias species are distributed on a single continent. The only remaining exception is Rhabdias fuscovenosa (Railliet, 1899), a parasite of snakes occurring in Europe, Asia, and North America. We believe, however, that a thorough study of the forms of the species from distant parts of its area, involving both morphological and molecular analysis, might reveal several sibling species within the $R$. fuscovenosa complex.

Differences between $R$. pseudosphaerocephala n. sp. and $R$. fulleborni are not very obvious. Bravo-Hollis and Caballero (1940) reported that $R$. sphaerocephala from Mexico $(=R$. pseudosphaerocephala) was shorter and had a postequatorial vulva. Kloss $(1971,1974)$ stated that " $R$. fulleborni differs from $R$. sphaerocephala by its slenderness, and by attaining a longer

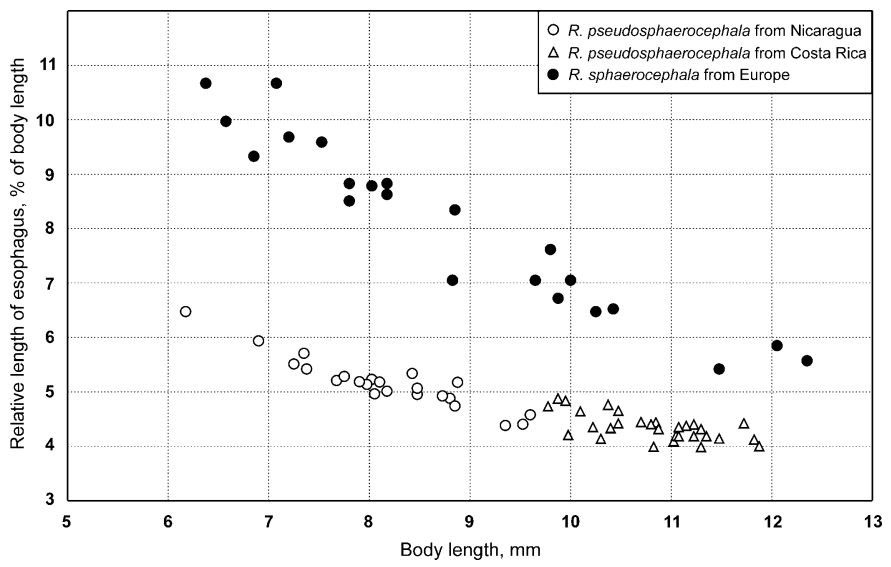

FIGURE 5. Relationship of the relative length of esophagus (percentage of total length) to the total length in $R$. pseudosphaerocephala sp. nov. and $R$. sphaerocephala. 
length" (Kloss, 1971). Apparently, the slenderness of any Rhabdias sp. is quite a subjective character, and the body length in both species is very similar. We add the relative length of esophagus as additional character for the separation of these species.

\section{ACKNOWLEDGMENTS}

We are grateful to the scientific and technical staff of the ACG for support of this study, in particular, Elda Araya, Roger Blanco, Carolina Cano, Maria Marta Chavarría, Felipe Chavarría, Roberto Espinoza, Dunia Garcia, Guillermo Jimenez, Elba Lopez, Sigifredo Marin, Alejandro Masis, Calixto Moraga, Fredy Quesada, and Petrona Rios. Thanks also to Dan Janzen and Winnie Hallwachs, scientific advisers to the ACG, for their support. Thanks to Derek Zelmer and Stephen Curran and for their assistance in collecting amphibians and their parasites. We are grateful to Edward Carlson for permission to use the facilities at the Imaging Center of the University of North Dakota Medical School and Donna Laturnus for her expert technical assistance during SEM observations. This study was funded by a research grant from the Natural Sciences and Engineering Research Council (NSERC) of Canada to D.R.B. and by the National Science Foundation through North Dakota EPSCoR (grant 0132289) to Y.K. and V.V.T.

\section{LITERATURE CITED}

BAKER, M. R. 1978. Morphology and taxonomy of Rhabdias spp. (Nematoda: Rhabdiasidae) from reptiles and amphibians of southern Ontario. Canadian Journal of Zoology 56: 2127-2141.

. 1979. The free-living and parasitic development of Rhabdias spp. (Nematoda: Rhabdiasidae) in amphibians. Canadian Journal of Zoology 57: 161-178.

Bravo-Hollis, M., and E. C. Caballero. 1940. Nematodes parasitos de los batracios de Mexico. IV. Anales del Instituto Biología, Universidad Nacional Autónoma de México 11: 239-247.

Brenes, R. R., AND M. Bravo-Hollis. 1959. Helmintos de la Republica de Costa Rica. VIII. Nematoda 2. Algunos nematodes de Bufo marinus marinus (L.) y algunas consideraciones sobre los generos $O x$ ysomatium y Aplectana. Revista de Biología Tropical 7: 35-55.

Chabaud, A. G., E. R. Brygoo, and A. G. Petter. 1961. Description et caracteres biologiques de deux noveaux Rhabdias malgaches. Annales de Parasitologie Humaine et Comparee 36: 752-763.

Goodey, T. 1924. Two new species of the nematode genus Rhabdias Journal of Helminthology 2: 203-208.

HaLl, T. A. 1999. BioEdit: A user-friendly biological sequence alignment editor and analysis program for Windows 95/98/NT. Nucleic Acids Symposium Series 41: 95-98.

HaRTwich, G. 1975. Schlauchwurmer, Nemathelminthes Rund-oder Fadenwurmer, Nematoda Parasitische Rundwurmer von Wirbeltieren. I. Rhabditida und Ascaridida. Die Tierwelt Deutschlands, 62 Tiel. Gustav Fischer Verlag, Jena, Germany, 256 p.

Hsu, W. 1960. Notes on some parasitic nematodes obtained from vertebrates in Nanking. Acta Zoologica Sinica 12: 101-108 109-113.

KLoss, G. R. 1971. Alguns Rhabdias (Nematoda) de Bufo no Brasil. Papeis Avulsos de Zoologia, São Paulo 24: 1-52.

. 1974. Rhabdias (Nematoda, Rhabditoidea) from the marinus group of Bufo. A study of sibling species. Arquivos de Zoologia, São Paulo 25: 61-120.

Kung, C. C., AND H. W. Wu. 1945. Parasitic nematodes of amphibians from Pehpei Szechwan, China. Sinensia 16: 73-83.

KuZmin, Y. I. 1997. The life cycle and the new data on distribution of Rhabdias sphaerocephala (Nematoda, Rhabdiasidae). Vestnik Zoologii 31: 49-57.

- 2001. Rhabdias africanus sp. nov. (Nematoda: Rhabdiasidae)-A new nematode species from the South African toads (Amphibia: Bufonidae). Acta Parasitologica 46: 148-150.

Lu, S. C. 1934. On Rhabdias, a genus of parasitic Nematoda of Nanking. Sinensia 5: 164-172.

TKaCh, V., AND J. PAWlowsKi. 1999. A new method of DNA extraction from the ethanol-fixed parasitic worms. Acta Parasitologica 44: 147-148.

, Y. KuzMin, AND E. E. Pulis. 2006. Rhabdias bakeri sp. n. from lungs of wood frog, Rana sylvatica, in North America: the las sibling of Rhabdias ranae? Journal of Parasitology 92: 631-636. 